Original Article

\title{
ANTIMICROBIAL PROFILES, ANTIDIARRHEAL AND ANTIPYRETIC CAPACITIES OF PHENOL ACID RICH-FRACTIONS FROM XIMENIA AMERICA L., (OLACACEAE) IN WISTAR ALBINO RATS
}

\author{
KONATE KIESSOUN ${ }^{1,2,6 *}$, MEDA NAG TIERO ROLAND ${ }^{3}$, DIAO MAMOUNATA ${ }^{1}$, KASSI YOMALAN $^{4}$, OKSANA SYTAR $^{5}$, \\ ALAIN SOUZ ${ }^{6}$, MARIAN BRESTIC ${ }^{7}$, MAMOUDOU HAMA DICKO ${ }^{1}$
}

\begin{abstract}
${ }^{1}$ Laboratory of Food Biochemistry, Enzymology, Biotechnology, and Bioinformatics, University of Ouagadougou, 03 P. 0. Box: 848, Ouagadougou 03, Burkina Faso, ${ }^{2}$ University of Dedougou, Burkina Faso. Training and Research Unit in Applied and Technological Sciences, P. O. Box 176, Dedougou, Burkina Faso, ${ }^{3}$ Laboratory of Research and Teaching in Animal Health and Biotechnology, University Nazi Boni of Bobo Dioulasso, 01 P. O. Box 1091, Bobo Dioulasso 01, Burkina Faso, ${ }^{4}$ Laboratory of Animal Physiology, UFR Bioscience, University of Felix Houphouet Boigny of Abidjan, 22 P. 0. Box 582, Abidjan 22, Ivory Cost, ${ }^{5}$ Department of Plant Physiology and Ecology, Taras Shevchenko National University of Kyiv, Volodymyrs'ka Street 64, Kyiv 01601, Ukraine, ${ }^{6}$ Laboratory of Animal Physiology, Electrophysiology and Pharmacology, Faculty of Sciences, University of Science and Technology of Masuku, Franceville, Gabon, ${ }^{7}$ Department of Plant Physiology, Slovak Agriculture University in Nitra, A. Hlinku 2, 94976 Nitra, Slovakia
\end{abstract}

Email: mehekiessoum@yahoo.fr

Received: 25 Feb 2018 Revised and Accepted: 03 Sep 2018

\section{ABSTRACT}

Objective: The present study aim to evaluate antimicrobial and antidiarrheal activities of phenol acid-rich fractions of roots from Ximenia americana L., in animal models in order to confirm the ethnomedicinal use of Ximenia Americana L., roots.

Methods: In vitro antibacterial (Minimum inhibitory concentration (MIC), Minimum bactericidal concentration (MBC) and time-kill studies) of phenol-rich fractions of roots from Ximenia americana L., was assessed using eight bacteria strains (Gram-negative). The anti-diarrheal activity was evaluated using castor using castor oil induced diarrhea whereas Anti-secretory activity was investigated using castor oil-induced enteropooling assay examined in animal models respectively.

Results: All test bacteria were susceptible to the phenol-rich fractions. Time-kill results showed that after $5 \mathrm{~h}$ exposition there was no viable microorganism in the initial inoculum. Moreover, phenol acid-rich fractions of roots (100-200 and $300 \mathrm{mg} / \mathrm{kg}$, p. o.) produced dose-dependent and significant $(\mathrm{p}<0.05-0.001)$ protection of rats against castor oil-induced diarrhea, and delayed gastric emptying. Phenol acid-rich fractions of roots, dose-dependently and significantly $(\mathrm{p}<0.05-0.001)$ delayed the onset of castor oil induced diarrhea, decreased the frequency of defecation, and reduced the severity of diarrhea in the rats. Phenol acid-rich fractions caused dose-related inhibition of castor-oil-induced enteropooling in rats.

Conclusion: The data analysis indicates that the tested of phenol-rich fractions has significant effects when compared with the standard antibiotic These results, therefore, justify the traditional use of Ximenia americana L. About antidiarrheal activity, the findings of this study indicate that phenol acid-rich fraction possesses antidiarrheal property in rats. These findings confirm the ethnomedicinal use of Ximenia americana L., roots valuable natural remedy for the treatment, management and/or control of diarrhea.

Keywords: Ximenia americana L., Phenol acid-rich fractions, Roots, Antimicrobial and antidiarrheal capacities

(C) 2018 The Authors. Published by Innovare Academic Sciences Pvt Ltd. This is an open access article under the CC BY license (http://creativecommons.org/licenses/by/4.0/) DOI: http://dx.doi.org/10.22159/ijpps.2018v10i10.25485

\section{INTRODUCTION}

Traditional cures and plant-based remedies remain the main solution to health problems in many developing countries [1]. According [2], medicinal plants usefulness was estimated that over $80 \%$ of developing countries populations have resorted to traditional medicine. Plants have been used for medical treatments through much of human history, and such medicine is still widely practiced today. Plant parts such as leaves, seeds, bark, berries, sap, roots, or flowers are widely used for their medicinal property. Moreover, since the time immemorial, medicinal plants have played an invaluable role in the development of therapeutic agents. Currently, it is estimated that about $80 \%$ of people living in developing countries still rely on traditional medicine for their primary health care [3].

There are many medicinal plants that possess antidiarrheal activity with lesser side effects than the conventional drugs. Diarrheal disease is a leading cause of mortality and morbidity, especially in developing countries and is responsible for the death of millions of people each year. In developing countries, the majority of people almost exclusively use traditional medicines in treating all sorts of diseases, including diarrhea. WHO has encouraged studies for treatment and prevention of diarrheal diseases depending on traditional medical practices. This may reduce the mortality rate in developing countries due to diarrhea. Tannins, alkaloids, flavonoids, and terpenoids are the major constituents that are primarily responsible for the antidiarrheal activity of these medicinal herbs [4]. In Burkina Faso, a range of medicinal plants have been widely used for the management of diarrhea and related gastrointestinal disorders by traditional healers [5]. However, the safety and therapeutic potentials of some of these medicinal plants have not been validated yet. Among them, Ximenia americana L., is one of the popular medicinal plants being used in the traditional medicine.

Ximenia americana (Olacaceae) which is also known, is a shrub-like a plant found in abundance in the West African region. It usually flowers in the second part of the dry season, producing cream-white to greenish yellow flowers. The fruits are green but turn goldenyellow or red. The fruit when eaten is very refreshing and has an almond acid taste.

Phytochemical screening of the leaves and stem bark revealed the presence of saponins, glycosides, flavonoids, tannins, phenolics, alkaloids, quinones and terpenoids types. In addition, the plant is potentially rich in fatty acids and glycerides and the seeds contain derivatives cyanide [5].

It is reported that the plant is used in traditional medicine for treatment of malaria, fever, leprotic ulcers and skin infections of mixed origin in Northern parts of Nigeria [6]. The roots are used for treating abdominal pains, dysentery, inflamed joints and mouth ulcers [7]. In the ethnobotanical claims, and particularly in Burkina Faso, this plant 
and particularly the roots are used for treating abdominal pains, dysentery, diarrhea, as a poison antidote, and infectious diseases in children such as malaria, fever, pain, and also have antibacterial, antiinflammatory, analgesic and hepatoprotective properties [5]. However, there is no scientific report available in support of the antidiarrheal and antipyretic activities of phenol acid of Ximenia americana L., roots. In this fact, the aim of the present work was evaluated the antidiarrheal and antipyretic activities of phenol acid of Ximenia americana L., roots for to provide a scientific basis for the traditional use of this ethnomedicinal plant in Burkina Faso.

\section{MATERIALS AND METHODS}

\section{Plants material}

The vegetable materials (Fresh roots) of Ximenia america L., (Olacaceae) were collected in August 2014 in Dedougou, $230 \mathrm{Km}$ West of Ouagadougou, capital of Burkina Faso. The plants were botanically identified by Dr. Traoré Lassina from the plants Biology Department of the University of Koudougou. A voucher specimen (MR_12) was deposited at the Herbarium of the Laboratoire de Biologie et d'Ecologie Végétales, UFR/SVT of the University of Ouagadougou.

\section{Bacterial strains and antibiotic}

Microorganisms used in this study were isolated from clinical samples at Laboratory of the General Hospital of Ouagadougou in Burkina Faso. Commercially available antibiotic diffusion discs (Ciprofloxacin: 10 $\mu \mathrm{g} / \mathrm{disc}$ ) were purchased from Alkom Laboratories LTD. Clinical isolates were: Shigella dysenteriae, Shigella boydii, Shigella flexneri, Salmonella thyphi, Klebsiella pneumonia, Klebsiella arogenes, Escherichia coli, and Proteus mirabilis. The following microorganisms were all identified by the use of their biochemical profiles as recommended by the manual "Bactériologie Medical” [8].

\section{Chemicals}

Acetone, oil ether, dichloromethane were supplied by Fluka Chemie (Buchs, Switzerland) Mueller Hinton agar and broth, Mac Farland, saline solution ( $\mathrm{Nacl}$ ), dimethylsulfoxide (DMSO) were purchased from Shijiazhuang. Pharma. Group. Zhangnua (China). Metamezole sodium (Sigma), loperamide (Sigma) and castor oil (Sigma) were purchased from Sigma (St. Louis, USA).

\section{Animals handling}

Swiss NMRI mice (25-30 g) of both sexes were used for acute toxicity, and Wister albino rats (180-240 g) of both sexes were used for antidiarrhea and antipyretic activities. All animals were housed in cages under controlled conditions of $12 \mathrm{~h} \mathrm{light/and} 12 \mathrm{~h}$ without light and $25{ }^{\circ} \mathrm{C}$. They received pellets of food enriched with $20 \%$ protein and water ad libitum. They were deprived of food for $15 \mathrm{~h}$ (but with access to drinking water) and weighed before the experiments. In vivo studies were carried out in accordance with guidelines for the care of laboratory animals and ethical guidelines for the investigation of experimental pain in conscious animals [9].

\section{Preparation of aqueous acetone extract for acute toxicity study}

The field-grown fresh samples (roots) were washed with tap water followed by distilled water to remove the adhering dust particles. After blotting, the samples were air dried in the shade. The dried plant materials (roots) were ground to fine powder and stored in clean airtight containers. A sample of $50 \mathrm{~g}$ of stem barks was placed in the soxhlet and run by using $80 \%$ aqueous acetone $(500 \mathrm{ml})$ in $1 / 10$ ratio $(\mathrm{w} / \mathrm{v})$ for $24 \mathrm{~h}$ under mechanic agitation at room temperature. After filtration, all the extracts were dried in a vacuum rotary evaporator at $40{ }^{\circ} \mathrm{C}$ under reduced pressure. Extracts were weighed and stored at $4^{\circ} \mathrm{C}$ for further analysis.

\section{Fractionation of phenol acid-rich fractions for antidiarrhea and antipyretic activities}

Fifty grams $(50 \mathrm{~g})$ of powdered plant material was extracted with $80 \%$ aqueous acetone $(500 \mathrm{ml})$ in $1 / 10$ ratio $(\mathrm{w} / \mathrm{v})$ for $24 \mathrm{~h}$ under mechanic agitation (SM 25 shaker, Edmund BÜHLER, Germany) at room temperature. After filtration, acetone was removed under reduced pressure in a rotary evaporator (BÜCHI, Rotavapor R-200, Switzerland) at approximately $40{ }^{\circ} \mathrm{C}$. The aqueous extracts were subjected to sequential liquid-liquid extraction with oil either to remove chlorophyll and other low molecular weight compounds and dichloromethane. This fraction (dichloromethane fraction) was then collected and concentrated to dryness under reduced pressure to obtain phenol acids (dichloromethane fraction). The fraction was freeze-dried by Telstar Cryodos 50 freeze-dryer. The fraction residues were packed in waterproof plastic flasks and stored at $4{ }^{\circ} \mathrm{C}$ until use. For the tests, the lyophilized sample was dissolved with $10 \%$ DMSO in water at the desired concentration [5].

\section{In vitro antimicrobial profile of phenol acid-rich fractions}

\section{Preparation of inocula}

The susceptibility tests were performed by the Mueller Hinton agarwell diffusion method [10]. The bacterial strains grown on nutrient agar at $37^{\circ} \mathrm{C}$ for $18 \mathrm{~h}$ were suspended in a saline solution $(0.9 \%, \mathrm{w} / \mathrm{v})$ $\mathrm{NaCl}$ and adjusted to a turbidity of $0.5 \mathrm{Mac}$ Farland standard $(108 \mathrm{CFU} / \mathrm{ml})$. To obtain the inocula, these suspensions were diluted 100 times in Muller Hinton broth to give 106colony forming units (CFU)/ml [11].

\section{Preparation of discs}

The stock solutions of phenol acid-rich fractions of roots from Ximenia americana L., was dissolved in 10\% dimethylsulfoxide (DMSO) in water [12] at a final concentration of $100 \mu \mathrm{g} / \mathrm{ml}$ after a serial two-fold dilution. Each stock solution of phenol acid-rich fractions was sterilized by filtration through $0.22 \mu \mathrm{m}$ sterilizing Millipore express filter. The sterile discs $(6 \mathrm{~mm})$ were impregnated with $10 \mu \mathrm{L}$ of the sterile phenol acid-rich fractions. Negative controls were prepared using discs impregnated with 10\% DMSO in water and commercially available antibiotic diffusion discs (Ciprofloxacin) from Alkom Laboratories LTD) were used as positive reference standards $(10 \mu \mathrm{g} / \mathrm{disc})$ for all bacterial strains.

\section{Disc-diffusion assay}

Petri plates $(9 \mathrm{~cm})$ were prepared with $20 \mathrm{ml}$ of a base layer of molten Mueller Hinton agar (DIFCO, Becton Dickinson, USA). Each Petri plate was inoculated with $15 \mu \mathrm{l}$ of each bacterial suspension $\left(10^{6} \mathrm{CFU} / \mathrm{ml}\right)$. After drying in a sterile hood, $6 \mathrm{~mm}$ diameter discs soaked with $10 \mu \mathrm{l}$ of the different phenol acid-rich fractions dilutions were placed on the agar.

Discs containing Ciprofloxacin $(10 \mu \mathrm{g} / \mathrm{disc})$ were used as positive controls and $10 \%$ DMSO was used as a negative control. The plates were incubated for $24 \mathrm{~h}$ at $37^{\circ} \mathrm{C}$ and at $44{ }^{\circ} \mathrm{C}$ for Escherichia coli because this bacterium is thermo-resistant. The diameters of the inhibition zones were evaluated in millimeters. The phenol acid-rich fractions inducing inhibition zone $\geq 3 \mathrm{~mm}$ around disc were considered as antibacterial. All tests were performed in triplicate, and the bacterial activity was expressed as the mean of inhibition diameters (mm) produced [13].

\section{Micro-well dilution assay}

Minimum inhibitory concentration (MIC) was determined by the microdilution method in culture broth as recommended by [14]. Eight serial two-fold dilutions of phenol acid-rich fractions were prepared as described before, to obtain a final concentration range of 400 to $3.125 \mu \mathrm{g} / \mathrm{ml}$. The 96 -well micro-plates (NUNC, Danemark) containing $100 \mu \mathrm{L}$ of Mueller Hinton (MH) broth were used. For each bacteria strain, three columns of eight wells to the micro-plate were used. Each well has getting: the culture medium+phenol acid-rich fractions+inoculum $(10 \mu \mathrm{l}$ of inocula) and INT $(50 \mu \mathrm{l} ; 0.2 \mathrm{mg} / \mathrm{ml})$. The plates were covered and incubated at $37{ }^{\circ} \mathrm{C}$ and at $44{ }^{\circ} \mathrm{C}$ for Escherichia coli for $24 \mathrm{~h}$. All tests were performed in triplicate and the bacterial activity was expressed as the mean of inhibitions produced. Inhibition of bacterial growth was judged by rose or yellow colour. The MIC was defined as the lowest concentration of extract or fraction of extract at which no colony was observed after incubation. So, the MIC was defined as the lowest concentration at which no visible growth was observed.

\section{Minimal bactericidal concentration (MBC)}

Minimum bactericidal concentration (MBC) was recorded as a lowest phenol acid-rich fractions concentration killing $99.9 \%$ of the 
bacterial inocula after $24 \mathrm{~h}$ incubation at $37{ }^{\circ} \mathrm{C}$. Each experiment was repeated at least three times. MBC values were determined by removing $100 \mu \mathrm{l}$ of bacterial suspension from subculture demonstrating no visible growth and inoculating nutrient agar plates. Plates were incubated at $37{ }^{\circ} \mathrm{C}$ for a total period of $24 \mathrm{~h}$.

The MBC is determined with the wells whose the concentrations are $\geq$ MIC $[13,15]$. The MBC was determined in Mueller Hinton (MH) agar (DIFCO, Becton Dickinson, USA) medium.

\section{Evaluation of bactericidal and bacteriostatic capacity}

The action of an antibacterial on the bacterial strains can be characterized with two parameters such as Minimum inhibitory concentration (MIC) and Minimum bactericidal concentration (MBC). According to the ratio $\mathrm{MBC} / \mathrm{MIC}$, we appreciated antibacterial activity. If the ratio $\mathrm{MBC} / \mathrm{MIC}=1$ or 2 , the effect was considered as bactericidal but if the ratio $\mathrm{MBC} / \mathrm{MIC}=4$ or 16 , the effect was defined as bacteriostatic [16].

\section{Time-kill assay}

A bactericidal effect is defined as a $3 \mathrm{Log}$ decrease in the $\mathrm{CFU} / \mathrm{ml}$ or a $99.9 \%$ kill over a specified time [17]. The definition of kill for this study has been used as per [18]. Kill-time can be determined at $6 \mathrm{~h}$ [19]. A $90 \%$ kill at $6 \mathrm{~h}$ is equivalent to a $99.9 \%$ kill at $24 \mathrm{~h}$ [20]. In this study, the kill measurement was determined by the actual reduction in viable counts at $6 \mathrm{~h}$ for each isolate. Bacteria strains possessing the bactericidal effect were chosen to perform the time-kill assay. Thus, 0.5 Mac Farland standards suspensions of the microorganisms were diluted to have $50 \mathrm{ml}$ of approximately $10^{6} \mathrm{CFU} / \mathrm{ml}$ in nutriment broth, and the concentration corresponding to the best MIC, were respectively added to the corresponding culture. The cultures were incubated at $37^{\circ} \mathrm{C}$. At $0,1,2,3,4,5$ and $6 \mathrm{~h}$, an aliquot of $100 \mu \mathrm{l}$ was removed and diluted with $10 \mathrm{ml}$ sterile broth. The obtained suspension was used to inoculate $9 \mathrm{~cm}$ diameter Petri plates with a sterile, nontoxic cotton swab on a wooden applicator as indicated before in the agar-well diffusion assay. After $24 \mathrm{~h}$ incubation at $37^{\circ} \mathrm{C}$, the viability of the microorganisms was evaluated by the presence of colonies on the plates. The experiment was carried out twice following [21] method with light modifications.

\section{Biological activities}

\section{Acute toxicity study in mice of aqueous acetone extract}

Healthy male and female Swiss mice $(25-30 \mathrm{~g})$ were randomly divided into 7 groups (1 control group and 6 treated assay groups) of 6 animals ( 3 male and 3 female). The control group received water containing 10\% dimethylsulfoxide (DMSO) administered intraperitoneally. The water/acetone of extract of roots from Ximenia americana L., suspended in 10\% DMSO was administered respectively intra-peritoneally at doses of $1 ; 2 ; 2.5 ; 3 ; 4 ; 5$ and $6 \mathrm{~g} / \mathrm{kg}$. The general behavior of the mice was observed for $120 \mathrm{~min}$ after the treatment. The animals were observed for morbidity and mortality once a day for $14 \mathrm{~d}$. The number of survivors after the $14 \mathrm{~d}$ periods was noted. The toxicological effect was assessed on the basis of mortality for $14 \mathrm{~d}$, which was expressed as the median lethal dose (LD50) (Lethal Dose 50) was estimated from the regression of logprobit mortality rate [22].

\section{Antipyretic activity test}

The method described by [23] was used for studying the antipyretic effect of phenol-acid-rich fractions of roots from Ximenia americana L. Thirty rats of both sex weighing 180-240 grams were divided into five groups of six rats in each. All rats were made hyperthermic by subcutaneous injection of brewer's yeast in physiological saline in a dose of $1.5 \mathrm{~g} / \mathrm{kg} \mathrm{b}$. wt. After $17 \mathrm{~h}$, the initial body temperature of each rat was measured rectally using a medical thermometer. The first group was kept as control; the second group was given metamezole sodium $50 \mathrm{mg} / \mathrm{kg} \mathrm{b}$. wt. as a standard antipyretic. The third, fourth and five groups were used to reveal the antipyretic effect of the tested phenol-acid-rich fractions of roots from Ximenia americana L., when given orally in a dose of 200, 250 and $300 \mathrm{mg} / \mathrm{kg}$ body weights, respectively. The body temperature of each rat was then recorded every hour for 3 successive hours.

\section{Antidiarrheal activity test \\ Castor oil-induced diarrhea}

The method of Awouters was followed for carrying out the study [24]. Rats of both sexes were fasted (without food, but water) for $18 \mathrm{~h}$. The selected rats for castor oil-induced diarrheal test were divided into five groups $(\mathrm{n}=10)$. Animals in the positive control groups received loperamide $(5 \mathrm{mg} / \mathrm{kg})$ body weight, and the control group received $0.9 \%$ normal saline $(2 \mathrm{ml} / \mathrm{kg}$ ) orally while those in the test groups received phenol-rich acid fractions at the doses of 100,200 , and $300 \mathrm{mg} / \mathrm{kg}$ body weight. After $1 \mathrm{~h}$, all groups received castor oil $1 \mathrm{ml}$ each orally. Then they were placed in cages lined with adsorbent papers and observed for $4 \mathrm{~h}$ for the presence of characteristic diarrheal droppings. $100 \%$ was considered as the total number of feces of the control group the activity was expressed as \% inhibition of diarrhea. The percent (\%) inhibition of defecation was measured.

The percentage inhibition of defecation was:

$$
\% \text { inhibition }=\frac{[\mathrm{A}-\mathrm{B}]}{\mathrm{A}} \times 100
$$

Where $A$ is mthe ean number of defecation time caused by castor oil and $B$ is mean number of defecation time caused by drug or fraction.

\section{Castor oil-induced enteropooling assay}

Castor oil-induced enteropooling test helps to determine the prevention of fluid accumulation ability of fraction. The test animals were fasted (without food, but water) for $18 \mathrm{~h}$ prior to the commencement of the experiment. They were divided into five groups $(\mathrm{n}=10)$. Animals in the positive control groups received loperamide $(5 \mathrm{mg} / \mathrm{kg})$ body weight, and the control group received $0.9 \%$ normal saline $(2 \mathrm{ml} / \mathrm{kg}$ ) orally while those in the test groups received phenol acid-rich fractions at the doses of 100,200, and 300 $\mathrm{mg} / \mathrm{kg}$ body weight. Immediately after these administrations, $1 \mathrm{ml}$ of castor oil was administered orally to each rat in all the groups. After $30 \mathrm{~min}$, the rats were sacrificed. At half an hour, all rats were sacrificed, and the small intestine from (the pylorus to the caecum) was isolated. The intestinal contents were collected by milking into a graduated tube, and their volume was measured [25]. The inhibition of intestinal content was computed according to the following expression:

$$
\text { Mass of intestinal fluid }(\mathrm{g})=\frac{(\text { Control-Treatment })}{\text { Control }} \times 100
$$

\section{Statistical analysis}

The data were expressed as mean \pm Standard deviation (SD) of six determinations $(n=6)$. Results were analyzed by one-way ANOVA followed by Dunnett $t$-test using Prism 4 software. The level of significance was accepted at $p \leq 0.05$.

\section{RESULTS AND DISCUSSION}

\section{Antimicrobial profiles}

In this present study, ten bacteria strain (Gram-negative and Grampositive bacteria) were used. The antibacterial assays were performed by the agar-well diffusion and the broth microdilution methods; so that they could be qualified and quantified by inhibition zone diameters, Minimum inhibitory concentration (MIC), Minimum bactericidal concentration (MBC) and Time-kill assays. One noticed that the susceptibility of the bacteria to the phenol acid-rich fractions on the basis of inhibition zone diameters varied according to the microorganism, the results are reported in (table 1). There is a significant variation in the diameters of inhibition zone values (DIZ) of phenol acid-rich fractions (table 1). 
Table 1: Inhibition zone diameters $(\mathrm{mm})$ recorder in agar well diffusion assay using phenol acid-rich fractions from Ximenia americana and Ciprofloxacin $(10 \mu \mathrm{g} / \mathrm{disc})$

\begin{tabular}{lll}
\hline Microorganisms & Ciprofloxacin $\mathbf{1 0 \mu g )}$ & Phenol acid-rich fractions \\
\hline Proteus mirabilis & $21.66 \pm 0.58$ & $25.66 \pm 1.53$ \\
Shigella dysenteria & $22.00 \pm 1.00$ & $29.66 \pm 0.58$ \\
Shigella boydii & $22.66 \pm 0.58$ & $21.33 \pm 4.04$ \\
Shigella flexneri & nd & $23.66 \pm 4.93$ \\
Salmonella thyphi & $23.66 \pm 0.58$ & $29.00 \pm 1.00$ \\
Klebsiella pneumonia & $20.66 \pm 0.54$ & nd \\
Klebsiella arogenes & $19.66 \pm 0.58$ & $16.00 \pm 1.00$ \\
Escherichia coli & $18.00 \pm 0.58$ & $20.00 \pm 1.00$ \\
\hline
\end{tabular}

The results are the means of a number of the colonies \pm standard deviations.

\section{nd: no detected activity}

As for the micro-well dilution assay (MIC) and Minimum bactericidal concentration (MBC) of phenol acid-rich fractions, result varied according to the microorganism (table 2). The MIC values were ranged from 25 to $100 \mu \mathrm{g} / \mathrm{ml}$ and for the $\mathrm{MBC}$ values were ranged from 50 to $400 \mu \mathrm{g} / \mathrm{ml}$. The bactericidal and bacteriostatic effect of phenol acidrich fractions was determined using the ratio MBC/MIC (table 2).

Table 2: Bacteriostatic (-) and Bactericidal (+) effects of phenol acid-rich fractions of roots from Ximenia americana L

\begin{tabular}{lll}
\hline Microorganisms & MIC $(\boldsymbol{\mu g} / \mathbf{m l})$ & MBC $(\boldsymbol{\mu g} / \mathbf{m l})$ \\
\hline Proteus mirabilis & $25 \pm 0.00$ & $50 \pm 0.00$ \\
Shigella dysenteria & $50 \pm 00$ & $100 \pm 0.00$ \\
Shigella boydii & $25 \pm 0.00$ & $50 \pm 0.00$ \\
Shigella flexneri & $25 \pm 0.00$ & $50 \pm 0.00$ \\
Salmonella thyphi & $25 \pm 0.00$ & $50 \pm 0.00$ \\
Klebsiella arogenes & $100 \pm 0.00$ & $400 \pm 0.00$ \\
Escherichia coli & $100 \pm 0.00$ & $400 \pm 0.00$ \\
\hline
\end{tabular}

The results are the means of a number of the colonies \pm standard deviations, +: bactericidal effect,-: bacteriostatic effect.

Table 3: Viability of microorganisms after $6 \mathrm{~h}$ exposure of phenol acid-rich fractions of

\begin{tabular}{|c|c|c|c|c|c|c|c|}
\hline \multirow[t]{2}{*}{ Microorganisms } & \multicolumn{7}{|c|}{ Time-kill (h) } \\
\hline & Oh & 1h & $2 \mathrm{~h}$ & $3 h$ & $4 h$ & $5 h$ & $6 h$ \\
\hline Proteus mirabilis & $+(\mathrm{UC})$ & $+(\mathrm{UC})$ & $+(\mathrm{UC})$ & $+(\mathrm{UC})$ & 147 & 12 & - \\
\hline Shigella dysenteria & $+(\mathrm{UC})$ & $+(\mathrm{UC})$ & $+(\mathrm{UC})$ & $+(\mathrm{UC})$ & 102 & 10 & - \\
\hline Shigella boydii & $+(U C)$ & $+(U C)$ & $+(\mathrm{UC})$ & $+(\mathrm{UC})$ & 37 & - & - \\
\hline Shigella flexneri & $+(U C)$ & $+(\mathrm{UC})$ & $+(U C)$ & $+(\mathrm{UC})$ & 08 & - & - \\
\hline Salmonella thyphi & $+(U C)$ & $+(U C)$ & $+(U C)$ & $+(\mathrm{UC})$ & - & - & - \\
\hline
\end{tabular}

Roots from Ximenia americana L, the results are the means of a number of the colonies \pm standard deviations, + : For the presence of the colonies, -: for the absence of colonies

Concerning the time-kill assay of phenol acid-rich fractions (table 3), the results showed that after $5 \mathrm{~h}$ exposition there was no viable microorganism in the initial inoculums. The effect of phenol acidrich fractions was faster on Salmonella thyphi than the other bacteria strains (table 3).

\section{UC: uncountable}

Medicinal plants have long been utilized as a source of therapeutic agents worldwide [26]. Previous studies have been carried out in different parts of the globe to extract plant products for screening antibacterial activity [27]. Plants produce highly bioactive molecules that allow them to interact with other organisms in their environment. Many investigators have evaluated the bioactivity of plant extracts and the isolated constituents against the serious infectious organisms [28]. In Africa, for the treatment of several infections, indigenous medicinal plants are often the only means [29]. Infectious due to multidrug-resistant microorganisms, pose an important clinical problem. Many of the bacterial strains are resistant to the standard antibiotic (Ciprofloxacin etc.) comparatively to the phenol acid-rich fractions. One could say that the metabolites have been shown to be responsible for the therapeutic activity of plants [30]. According to a recent study, Ximenia americana L. contains saponins, glycosides, flavonoids, tannins, phenolics, alkaloids, quinones, and terpenoids types [5]. The natural products were found to possess promising antimicrobial, and the metabolites have been shown to be responsible for the therapeutic activity of plants [31].

The data analysis indicates that the tested polyphenol extract showed the significant results when compared with the standard antibiotic. Indeed, the antibacterial activity profile of the isolated constituents (polyphenols) when compared with antibiotic effects shows that the activity depends on the pure form of the constituents. This may be due to the fact that the bioactive constituents such as polyphenol compounds were responsible for the antimicrobial activity. In effect, some previous studies showed that polyphenolic compounds cause inhibition of a wide range of microorganisms. Phenol is well known as a chemical antiseptic [32].

In addition, Phenolic and terpenic antimicrobial activities are well documented [13]. Polyphenols, such as tannins and flavonoids, are important for antibacterial activity [29]. The antimicrobial activity of flavonoids is due to their ability to complex with extracellular and soluble protein and to complex with bacterial cell wall while that of tannins may be related to their ability to inactivate microbial adhesions, enzymes and cell envelop proteins [33]. Then, Polyphenols, such as tannins and flavonoids, are important antibacterial activity [34]. Also, polyphenols have a good antimicrobial activity against the biggest number of bacterial as such Escherichia coli, Proteus mirabilis, Salmonella typhimurium [35]. 
Our data noticed that certain bacteria are resistant to the standard antibiotic compared to the phenol acid-rich fractions. The resistance of these bacteria towards antibacterial substances is related to the hydrophilic surface of their outer membrane which is rich in lipopolysaccharide molecules, presenting a barrier to the penetration of numerous antibiotic molecules and is also associated with the enzymes in periplasme space, which are capable of breaking down the molecules introduced from outside [36]. The resistances of the bacteria to the current antibiotics necessitate the further studies on the isolated constituents to find out their safety and efficacy profile. This highlights the continuous interest in laboratory screening of medicinal plants, not only to determine the scientific rationale for their usage but also to discover new active principles. Briefly, our results indicate good in vitro antimicrobial activities.

\section{Acute toxicity study in mice}

The effect of intraperitoneal treatment of the aqueous acetone extract from Ximenia americana L., on mortality, $\mathrm{LD}_{50}$ is 3270.8 $\mathrm{mg} / \mathrm{Kg}$ body weight for intraperitoneal administration. No significant difference in body weight gain of the treated assay groups over the period of observation. No statistical difference was observed between the organ weights in the control and the intraperitoneal route groups. At acute toxicity level, data indicated that extract of Ximenia americana L., can be considered as weakly poisonous. According to Diez [21], pharmacological substances whole LD50 with less than $5 \mathrm{mg} / \mathrm{kg}$ body weight are considered not toxics; those with a LD50 between $5 \mathrm{mg} / \mathrm{kg}$ body weight and 5000 $\mathrm{mg} / \mathrm{kg}$ body weight are classified in the range of moderately toxic substances and those with the lethal dose is more than $5000 \mathrm{mg} / \mathrm{kg}$ body weight are classified in the range of highly toxic substances. In this fact, if we refer to this classification, we could say that the extract of Ximenia americana L., is moderately toxic and would be regarded as being safe or of low toxicity [22]. This is an indication that the aqueous acetone extract of Ximenia americana L., has negligible level of toxicity when administered orally.

\section{Antipyretic effects}

The antipyretic effect of phenol-acid rich fractions of roots was studied in hyperthermic rats using brewer's yeast and data were recorded in (table 4). The subcutaneous injection of brewer's yeast suspension markedly elevated rectal temperature after $17 \mathrm{~h}$ of administration. Oral administration of phenol-acid rich fractions of roots induced significant antipyretic activity at a dose of $300 \mathrm{mg} / \mathrm{kg} \mathrm{b}$. wt., while the low dose $250 \mathrm{mg} / \mathrm{kg}$ failed to decrease the raised body temperature. The effect of the high dose of $300 \mathrm{mg} / \mathrm{kg} \mathrm{b}$. wt., nearly similar to that of the standard metamezole sodium (50 mg/kg b. wt.) after $3 \mathrm{~h}$. Significance was indicated by lowering the body temperature were (36.66 \pm 0.14 and $36.85 \pm 0.11$ ) after $2 \mathrm{~h}$ of administration of the standard drug and root fractions, respectively and at $3 \mathrm{~h}(36.62 \pm 0.1$ and $36.81 \pm 0.15$ ) when compared to the control non-treated group.

Table 4: Antipyretic effect of phenol acid-rich fractions of roots from Ximenia americana L., hyperthermic rats (mean $\pm \mathrm{SE}, \mathrm{N}=6)$

\begin{tabular}{|c|c|c|c|c|c|}
\hline \multirow[t]{2}{*}{ Treatment } & \multirow[t]{2}{*}{ Dose (mg/Kg b. wt.) } & \multicolumn{4}{|c|}{ Rectal temperature $\left({ }^{\circ} \mathrm{C}\right)$} \\
\hline & & Before treatment & $\mathbf{1 h}$ & $2 \mathrm{~h}$ & $3 \mathbf{h}$ \\
\hline Control & 0 & $37.69 \pm 0.15^{b}$ & $37.63 \pm 0.1^{\mathrm{c}}$ & $37.57 \pm 0.14^{\mathrm{c}}$ & $37.68 \pm 0.2^{\mathrm{e}}$ \\
\hline Metamezole sodium (Standard) & 50 & $37.50 \pm 0.11^{\mathrm{a}}$ & $36.55 \pm 0.12^{\mathrm{a}}$ & $36.66 \pm 0.14^{\mathrm{a}}$ & $36.62 \pm 0.10^{a}$ \\
\hline \multirow[t]{3}{*}{ phenol acid-rich fractions } & 200 & $37.76 \pm 0.1^{\mathrm{c}}$ & $37.72 \pm 0.11^{\mathrm{d}}$ & $37.76 \pm 0.11^{\mathrm{e}}$ & $37.62 \pm 0.11^{\mathrm{d}}$ \\
\hline & 250 & $37.79 \pm 0.11^{\mathrm{d}}$ & $37.76 \pm 0.1^{\mathrm{e}}$ & $37.71 \pm 0.14^{\mathrm{d}}$ & $37.54 \pm 0.1^{c}$ \\
\hline & 300 & $37.83 \pm 0.2^{\mathrm{e}}$ & $37.10 \pm 0.2^{\mathrm{b}}$ & $36.85 \pm 0.11^{\mathrm{b}}$ & $36.81 \pm 0.15^{b}$ \\
\hline
\end{tabular}

Values represent the mean \pm SE of five animals for each group, values in each column with different superscript letters (a, b, c, d, e) are significantly different at $\mathrm{P}<0.05$.

About antipyretic potential, one could say that antipyretic activity may be attributed to the presence of phytochemical constituents such as $\beta$ sitosterol triterpenes, flavonoids, saponins, glycosides, tannins, and alkaloids [37]. The $\beta$-sitosterol reduces PG and leukotrienes synthesis and in turn shows anti-inflammatory and antipyretic activity by inhibiting the pro-inflammatory cytokines and TNF- $\alpha[38,39]$.

\section{Antidiarrheal affects}

\section{Castor oil-induced diarrheal model}

In case of castor-oil induced diarrheal model, phenol acid-rich fractions at the doses of 100,200 , and $300 \mathrm{mg} / \mathrm{kg}$, exerted statistically significantly $(p<0.001)$ decreased and dose-dependent inhibition of the total number of diarrheal feces compared with the control groups (table 5).

\section{Castor oil-induced enteropooling assay}

The administration of castor oil resulted in intestinal fluid volumes and weights of the intestinal contents of the rats (from the pylorus to the caecum) were statistically significantly $(p<0.001)$ and dose-dependently reduced by both phenol acidrich fractions at the doses of 200 , and $300 \mathrm{mg} / \mathrm{kg}$ compared to the control group (table 6).

Table 5: The antidiarrheal effect of phenol acid-rich fractions of roots from Ximenia americana L., on castor oil-induced diarrhea models in rats

\begin{tabular}{llllll}
\hline Treatment & Dose $\mathbf{~} \mathbf{m g} / \mathbf{k g})$ & Total number of feces & \% of inhibition & Total number of diarrheal feces & \% of inhibition \\
\hline Control & $2 \mathrm{ml} / \mathrm{kg}$ & $20.17 \pm 0.54 * 0.11$ & $-14.12 \pm 0.11$ & - \\
Loperamide & 5 & $9.02 \pm 0.67^{* * *}$ & 55.28 & $6.22 \pm 0.54^{* * *}$ & 55.94 \\
& 100 & $12.53 \pm 0.10^{*}$ & 37.87 & $7.89 \pm 0.37^{*}$ & 44.12 \\
phenol acid-rich & 200 & $10.21 \pm 0.37^{* * *}$ & 49.38 & $5.80 \pm 0.11^{* * *}$ & 58.92 \\
fractions & 300 & $8.02 \pm 0.63^{* * *}$ & 60.23 & $4.78 \pm 0.23^{* * *}$ & 66.15 \\
\hline
\end{tabular}

Each value is presented as the mean \pm SEM $(\mathrm{n}=10)$, phenol acid-rich fractions of roots from Ximenia americana $\mathrm{L}$., $* * * p<0.001$ compared with the control group (Dunnett's Test), ${ }^{* *} p<0.01$ compared with the control group (Dunnett's Test), ${ }^{*} p<0.05$ compared with the control group (Dunnett's Test).

Table 6: The Anti-secretory effect of phenol acid-rich fractions of roots from Ximeniaamericana L., on castor oil-induced enteropooling assay in rats

\begin{tabular}{lll}
\hline Treatment & Dose $(\mathrm{mg} / \mathrm{kg})$ & Volume of intestinal content (mL) \\
\hline Control & $2 \mathrm{ml} / \mathrm{kg}$ & $2.18 \pm 0.11$ \\
Loperamide & 5 & $0.63 \pm 0.45^{* *}$ \\
phenol acid-rich fractions & 100 & $1.12 \pm 1.63$ \\
& 200 & $0.96 \pm 0.53^{*}$ \\
& 300 & $0.78 \pm 0.10^{* *}$ \\
\hline
\end{tabular}

Each value is presented as the mean $\pm \operatorname{SEM}(\mathrm{n}=10),{ }^{* * *} p<0.001$ compared with the control group (Dunnett's Test), ${ }^{* *} p<0.01$ compared with the control group (Dunnett's Test), ${ }^{*} p<0.05$ compared with the control group (Dunnett's Test) 
Phenol acid-rich fractions of roots were evaluated for its antidiarrheal potential against castor oil induced diarrhea model in rats. In respect to demonstrate the probable mechanisms, the antisecretory effect was also tested using castor oil induced enteropooling assay in rats. Loperamide, the standard drug, generally produces rapid and sustained inhibition of the peristaltic reflex through depression of longitudinal and circular muscle activity. It is well known to reduce the daily fecal volume and decreases intestinal fluid and electrolyte loss. The antidiarrheal activity of, phenol acid-rich fractions of roots was comparable to the standard drug, loperamide, which at present is one of the most efficacious and widely employed antidiarrheal drugs. In our investigation, loperamide proved the claims by causing effectively antagonizes diarrheal activity induced by castor oil. It also decreases the number of diarrheal feces. It is widely known that castor oil is metabolized into ricinoleic acid in the gut, reduce active $\mathrm{Na}+$ and $\mathrm{K}+$ absorption and decrease $\mathrm{Na}+\mathrm{K}+\mathrm{ATPase}$ activity in the small intestine and colon. As with other laxatives, castor-oil changes the electrolyte permeability of the intestinal mucosal membrane [40]. In the castor-oil induced diarrhea model in rats, phenol acid-rich fractions of roots showed dose-dependent manner and significant $(p<0.001)$ reduced in the number of feces and the number of diarrheal feces with the percentage of inhibition (table 5). In the castor oil-induced enteropooling assay, castor oil produces permeability changes in the intestinal mucosal membranes to water and electrolytes resulting in fluid and watery luminal content that flows rapidly through the small and large intestines. The Antisecretory effect of phenol acid-rich fractions of roots significantly $(p<0.001)$ inhibited the castor oil-induced intestinal fluid accumulation. The intestinal content was, however, more viscous in extract treated than in control rats.

\section{CONCLUSION}

The present study thus proves that phenol acid-rich fractions of roots from Ximenia americana L., possesses on a one hand significant antimicrobial activities to treat infectious diseases due to multiresistant bacterial strains. On the other hand, the study also proves the anti-diarrheal activity of phenol acid-rich fractions of roots from Ximenia americana L., due to its inhibitory effect among castor oil induced diarrhea, and castor oil induced enteropooling assay. The study though supports the traditional claim; further studies are needed to identify the chemical constituents that are responsible for the antidiarrheal effect. In conclusion, it appears that the phenol acid-rich fractions of roots from Ximenia americana L., possesses antidiarrheal, anti-motility and anti-secretory activities and thus can be developed for use in the treatment of diarrhea.

\section{AUTHORS CONTRIBUTIONS}

All the author have contributed equally

\section{CONFLICT OF INTERESTS}

All the authors had equal contribution in the manuscript and declared no conflict of interests.

\section{REFERENCES}

1. Azaizeh H, S Fulder, $\mathrm{K}$ Khalil, $\mathrm{O}$ Said. Ethnomedicinal knowledge of local arab practition ersin the middle east region. Fitoterapia 2003;74:98-108.

2. OMS; 2003. Available from: http://ww.int/mediactre/ factsheets/ fs134/fr/. [Last accessed on 25 Feb 2018].

3. Pathak K, Das RJ. Herbal medicine-a rational approach in health care system. Int J Ayurvedic Herbal Med 2013;1:86-9.

4. Komal S, Kumar S, Rana A. Herbal approaches for diarrhea: a review. IRJP 2013;4:31-8.

5. Nacoulma OG. Medicinal plants and their traditional uses in Burkina Faso. Ph. D. Thesis: University of Ouagadougou; 1996. p. 328.

6. Ogunleye DS, Ibitoye SF. Studies of antimicrobial activity and chemical constituents of Ximenia americana. Trop J Pharm Res 2003;2:239-41.

7. Ake AI, Guinko S. In: Plants used in traditional medicine in West Africa. F. Hoffman, La Roche Ltd. Basel Switzerland; 1991. p. 100.
8. Le Minor L, Veron M. Bactériologie Médicale. Edited by: Flammarion medecine-sciences 773; 1984.

9. M Zimmermann. Ethical guidelines for investigations of experimental pain in conscious animals. Pain 1983;16:109-10.

10. Perez C, Pauli M, Bazerque P. An antibiotic assay by the agarwell diffusion method. Acta Biol Med Experimentalis 1990;15:113-5.

11. Ezoubeiri A, Gadhi CA, Fdil N, Benharref A, Jana M, Vanhaelen M. Isolation and antimicrobial activity of two phenolic compounds from Pulicariaodora L. J Ethnopharmacol 2005;99:287-92.

12. Pujol V, Villard J. Research of antifungal substances secreted by higherfungi in culture. French Pharm J 1990;48:17-22.

13. Rabe T, Mullholland D, van Staden J. Isolation and identification of antibacterial compounds from Vernonia colorata leaves. J Ethnopharmacol 2002a;80:91-4.

14. NCCLS-National Committee for Clinical Laboratory Standards. Performance standard for antimicrobial susceptibility testing: eleventh informational supplement. Document M100-S11. National Committee for ClinicalLaboratory Standard, Wayne, PA, USA; 2001a.

15. Traore R. Contribution has the study of the adhesion of enterobacteries of the kinds Klebsiella proteus and K serratia with the Human epithelial Cells Doctthesis science pharmaceutical. Universitélibre de Bruxelles; 1993. p. 158.

16. Berche P, Gaillard JL, Simonet M. In nosocomial infections caused by bacteriaand their prevention in bacteriology edited by: Flammarion Med Sci; 1988. p. 64-71.

17. Wolfe EF, Klepser ME, Pfaller MA. Antifungal dynamics of amphotericin Band fluconazole in combination against Candida albicans, effect of exposure time. Pharmacotherapy 1997; 17:189-9.

18. Rabe T, van Staden J. Antibacterial activity of South African plants used for medicinal purposes. J Ethnopharmacol 1997b; 56:81-7.

19. White RL, Bugess DS, Manduru M, Bosso JA. Comparison of three different in vitro methods of detecting synergy: Time-kill, chercher board, and Etest. Antimicrob Agents Chemother 1996;40:1914-8.

20. National Committee for Clinical Laboratory Standards: Methods for Determining Bactericidal Activity of Antimicrobial Agent. Wayne, Pa: National Committee for Clinacal Laboratory Standards; 1992b.

21. Karou D, Savadogo A, Canini A, Yameogo S, Montesano C, Simpore J, et al. Antibacterial activity of alkaloids from Sida acuta. Afr J Biotechnol 2006;5:195-200.

22. Miller LC, Tainter ML. Estimation of the LD50 and its error by means of logarithmic probit graph paper. Proceedings Soc Exp Biol Med 1944;57:261-4.

23. Alperman $\mathrm{H}$. Bericht uber pharmakologische untersuchungen mit fenbendazol. Abteilung Fur Pharmakologie 1972;863:1-9.

24. Awouters F, Niemegeers CJ, Kuyps J, Janssen PA. Loperamide antagonism of castoroil-induced diarrhea in rats: a quantitative study. Arch Int Pharmacodyn Ther 1975;217:29-37.

25. Robert A, Nezamis JE, Lancaster C, Hanchar AJ, Klepper MS. Enteropoolingassay: a test for diarrhea produced by prostaglandins. Prostaglandins 1976;11:809-28.

26. Malathi S, Sekar T, Sujatha S. Antimicrobial and free radical scavenging activity of leaf and stem extract of Limonia alata wight and ARN. Asian J Pharm Clin Res 2018;11:360-5.

27. Ravikumar S, Nazar S, Nuralshiefa A, Abideen S. Antibacterial activity of traditional therapeutic coastal medicinal plants against some pathogens. J Environ Biol 2005;26:383-6.

28. Parekh J, Sumitra C. In vitro antimicrobial of extracts of Launaea procumbens Roxb. (Labiateae), Vitisvinifera L. (Vitaceae) and cyperusrotundus L. (Cyperaceae). Afr J Biomed Res 2006;9:89-93.

29. Machado TD, Leal ICR, Amaral ACF, dos Santos KRN, da Siva MG, Kuster RM. Antimicrobial ellagitannin of Punicagranutum fruits. J Braz Chem Soc 2002;13:606-10.

30. Shrivastava SM, Kumar S, Chaudhary M. Time-kill curve studies of against Escherichia coli, Staphylococcus aureus, Klebsiella pneumonia and Proteus vulgaris. Res J Med Plant 2009;3:116-22. 
31. Jazani NH, Zartoshti M, Shahabi S, Yekta Z, Nateghi S. Evaluation of thesynergetic effect of water-soluble extracts of green tea (Camelliasinensis) on the activity of ciprofloxacin in urinary isolated E. coli. J Biol Sci 2007;7:1500-3.

32. Abeer M, Haj A, Sanaa OY. Anti-microbial activity of acacia nilotica extracts against some bacteria isolated from clinical specimens. Res J Med Plant 2007;1:25-8.

33. Cowan MM. Plants products as antimicrobial agents. Clin Microbiol Rev 1999;12:564-82.

34. Machado TD, ICR Leal, ACFA Maral, KRN dos Santos, MG da Siva et al. Antimicrobial ellagitannin of Punicagranutum fruits. J Brazilian Chem Soc 2002;13:606-10.

35. Scalbert A. Antimicrobial properties of tannins. Phytochemistry 1991;30:3875-83
36. Gao Y, Belkum MJV, Stiles M. The outer membrane of Gramnegative bacteria inhibits the antibacterial activity of Brochocin C. Appl Environ Microbiol 1999;65:4329-33.

37. Patel D Jayshree, Kumar Vipin. Annonasquamosa L. phytochemical analysis and antimicrobial screening. J Pharm Res 2008;1:34-8.

38. Gupta MB, Nath R, Srivastava N. Anti-inflammatory and antipyretic activities of beta-sitosterol. Int J Immunopharmacol 1996;18:693-7.

39. Bouic PJ, Lamprecht JH. Plant sterols and sterolins: a review of their immune-modulating properties. Altern Med Rev 1999;4:170-7.

40. Gaginella T, Phillips SF. Ricinoleic acid: a current view of ancient oil. Dig Dis Sci 1975;23:1171-7. 